\title{
O FENÔMENO DA ZONA DE PROCESSAMENTO DE EXPORTAÇÃO NO RIO GRANDE DO NORTE
}

Denílson da Silva Araújo ${ }^{1}$

Rebeca Marota da Silva ${ }^{2}$

RESUMO: Analisa a real contribuição das Zonas de Processamento de Exportações (ZPEs), no mundo, no Brasil e, em particular, no Rio Grande do Norte no que tange a integração econômica de diferentes áreas produtivas e a dinamização de seus processos de crescimento e de desenvolvimento econômicos. A partir do debate nacional entre os que são a favor e os que são contra a implantação de zonas de exportações em regiões específicas, a análise parte do registro da importância das ZPEs em países que optaram em diferentes momentos históricos, para o aumento dos investimentos produtivos e para a diversificação da produção e de suas exportações a partir da inovação, notadamente em suas políticas fiscais. Nesses países desenvolvidos e em desenvolvimento as ZPEs mostraram-se muito mais eficientes no que tange a captação de novos blocos industriais, de aumento de produção e de exportações mais elaboradas. Conclui-se que essa eficiência não tem se manifestado no Brasil, onde as ZPEs funcionam de forma não integrada a um projeto nacional de industrialização e muito menos no Rio Grande do Norte, onde o fenômeno da ZPE é significativamente ineficiente e por esse motivo não passa de um mito quanto à sua contribuição para o desenvolvimento e a integração econômica estadual.

Palavras-Chave: Zona de Processamento de Exportação; Economia Potiguar; Desenvolvimento Regional, Planejamento Econômico. Economia Regional.

\footnotetext{
1 Mestre em Estudos Urbanos e Regionais (UFRN). Graduada em Economia (UFRN). E-mail: rebeca.economia@gmail.com.

2 Doutor em Economia pela Universidade Estadual de Campinas (UNICAMP) e Professor do Departamento de Economia (UFRN). E-mail: araujodenilson@hotmail.com.
} 


\section{INTRODUÇÃO}

No presente texto buscou-se fazer uma sucinta análise acerca do impacto de uma Zona de Processamento de Exportação (ZPE) sobre o crescimento e o desenvolvimento econômico de diversos países desenvolvidos e em desenvolvimento. Em contexto mais específico, fez-se também uma abordagem da importância da ZPE como instrumento estratégico para a ampliação das exportações e modernização tecnológica das indústrias do Rio Grande do Norte que forem produzir em uma de suas instalações.

Inicialmente foi feito um esforço no sentido de tornar clarividente o que é uma ZPE e quais são, de fato, seus principais efeitos econômicos. Em seguida, fez-se uma explanação acerca da efetiva utilização das ZPEs - no mundo - e a importância de sua disseminação no Brasil como instrumento de dinamização das exportações e de atração de investimentos produtivos internacionais com o estrito propósito em operações exportadoras. Nesse ponto, foram devidamente registrados os principais países e continentes que têm praticado comércio exterior através de suas ZPEs.

Na periferia capitalista, mas notadamente no Brasil, o fenômeno das ZPEs tem suscitado calorosos debates entre os seus críticos e defensores. O resultado concreto do aludido debate é de suma importância para o destino das exportações brasileiras. Por essa razão, buscou-se registrá-lo na perspectiva de esclarecer as principais dúvidas que ainda resistem aos exemplos de sucesso dos casos concretos do uso de ZPEs como instrumento de política econômica voltado especificamente para o crescimento, para a criação de emprego e geração de renda, para a disseminação de tecnologias e novos métodos produtivos e para ajudar a combater os indesejáveis desequilíbrios econômicos.

Na perspectiva de colocar mais elementos esclarecedores acerca do que é uma ZPE e quais devem ser seus verdadeiros efeitos, imediatamente ao registro do debate, foram elencadas as principais vantagens e desvantagens da criação e utilização de uma ZPE como instrumento de incentivo às exportações. Especificamente foi dado relevo à importância da modernização da Legislação das ZPEs no Brasil desde 1988 (quando foram formalmente criadas) até o ano de 2008/2009. Essa modernização eivou 
de possibilidades positivas a utilização de ZPEs no Brasil dado que criou as condições necessárias para que as empresas brasileiras que irão produzir em ZPE possam desfrutar das mesmas vantagens de suas concorrentes internacionais.

Por fim, foi realizado um breve registro sobre a futura existência das ZPEs do estado do Rio Grande do Norte. Nesse último, existem em processo de instalação duas ZPEs: uma na Região Metropolitana de Natal, no município de Macaíba, e outra no interior do estado, no município de Assú, ambas de grande importância, segundo os especialistas, para o crescimento da produção e das exportações potiguares, para contribuição na criação de empregos e geração de renda e para, sobretudo, fortalecer o processo de integração da economia potiguar às economias nacional e internacional.

Deve ser observado que para a construção do corrente texto foram utilizadas como fontes de pesquisa algumas publicações especializadas no tema, matérias de jornais e sítios eletrônicos que dedicaram especial atenção à temática em âmbito internacional, nacional e estadual. Acrescente-se às fontes anteriormente citadas, entrevistas com representantes de instituições que, no estado do Rio Grande do Norte, estão diretamente à frente do processo de discussão e de instalação das ZPEs estaduais, tais como: a Secretaria de Estado do Planejamento e das Finanças do Rio Grande do Norte e a Federação das Indústrias do Estado do Rio Grande do Norte.

\section{AS ZPES NO MUNDO E NO BRASIL}

2.1. O QUE É UMA ZPE, SEUS PRINCIPAIS OBJETIVOS E EFEITOS ECONÔMICOS.

Uma Zona de Processamento de Exportação (ZPE) é, na verdade, um distrito industrial incentivado onde se concede às empresas nele instaladas isenção de impostos e liberdade cambial $^{3}$ em suas operações produtivas. A principal condição imposta às empresas é que exportem $80 \%$ de sua produção, podendo vender os restantes $20 \%$ no mercado interno, porém sujeito as mesmas condições de qualquer outra empresa que não se encontra sob as determinações jurídicas de uma ZPE.

3 Isso significa que as empresas não são obrigadas a fazer a conversão para moeda nacional das divisas obtidas nas exportações. 
Nesses termos, o percentual vendido no mercado interno estará sujeito às cobranças de impostos de importação (de matéria-prima, máquinas e equipamentos, por exemplo).

Existe em âmbito nacional um programa específico sobre Zonas de Processamento de Exportação. O referido Programa é administrado pelo Conselho Nacional das Zonas de Processamento de Exportação (CZPE), composto pelos Ministros do Desenvolvimento, Indústria e Comércio Exterior (que preside o Conselho), pelo Ministério da Fazenda, da Integração Nacional, do Meio Ambiente e do Planejamento.

É praticamente um consenso mundial que a ZPE funciona como um instrumento que tem como principal objetivo atrair investimentos estrangeiros voltados às exportações, permitindo que as empresas nacionais disponham de iguais condições de produção de suas concorrentes de outros países que são contempladas por benesses fiscais por estarem situadas em uma ZPE ou por disporem de outros tipos de subsídios para exportação. Ademais, os principais objetivos da ZPE são: criar empregos; contribuir para fortalecer o balanço de pagamentos; aumentar o valor agregado das exportações; difundir e homogeneizar as forças produtivas (tecnologias) e as modernas práticas de gestão além de corrigir os desequilíbrios regionais.

No Brasil, como se verá adiante, a ZPE é uma estrutura econômica em processo de gestação, porém, em âmbito internacional, alguns estudos de caso comprovam que os principais objetivos das ZPEs foram atingidos a contento e em várias realidades a experiência teve participação incisiva no crescimento econômico regional ${ }^{4}$.

Nos casos de sucesso das ZPEs, a atração de empresas internacionais para as referidas Zonas assegurou não apenas maior dinamismo como também melhores condições de operação para as empresas nacionais, pertencentes ou não a ZPE, dado o maior adensamento produtivo (manufatureiro e de serviços) que o capital estrangeiro foi capaz de atrair. A passagem abaixo revela a importância da ZPE como instrumento de atração do capital internacional e para o dinamismo das exportações:

4 Ver em especial o estudo realizado pelo IEDI (2002) para os casos dos seguintes países: México, Costa Rica, Irlanda, Israel, Índia, Taiwan, China, Coréia do Sul e Malásia. 
A experiência internacional mostra que os países mais bem-sucedidos na exportação de produtos manufaturados recorrem extensivamente a um instrumento concebido especialmente para atrair empresas estrangeiras para exportar a partir de seus territórios, e simultaneamente assegurar às empresas nacionais condições competitivas comparáveis às que dispõem seus concorrentes no mercado internacional - que são as "zonas francas industriais" ou "zonas de processamento de exportação - ZPEs". (BRAGA, 2003, p. 2)

A preocupação de utilizar as ZPEs como instrumento catalisador de investimentos estrangeiros passou a ter maior peso, notadamente em economias subdesenvolvidas onde o discurso oficial alega, como no Brasil, que nessas economias existem vastas áreas que carecem de maior atenção quanto à matéria, dado em parte, o baixo nível de concentração industrial das mesmas. Mas, nesse ponto, aflora um grande obstáculo para o sucesso das ZPEs nas regiões subdesenvolvidas da periferia capitalista. As indústrias instaladas nessas regiões não são essencialmente exportadoras além de serem pouco intensivas em tecnologia de ponta ${ }^{5}$. Mesmo as que exportam fazem parte dos gêneros de indústrias tradicionais como: as indústrias de alimentos, as de bebidas, as têxteis e de confecções e, em determinadas fases de aumento da demanda internacional, as de minérios ${ }^{6}$.

Embora haja exportação para o exterior, tomando como referência a produção industrial das regiões menos desenvolvidas, pode-se afirmar com alto grau de confiança que tais exportações são quantitativamente inexpressivas e qualitativamente de baixo valor agregado. Por essa razão, mesmo que se instale ZPEs nas mesmas fazse de essencial importância aumentar o esforço exportador com a participação do capital estrangeiro ${ }^{7}$.

A experiência internacional tem evidenciado que as ZPEs que obtiveram maiores sucessos são exatamente aquelas que internalizaram refinarias de petróleo, indústrias automobilísticas, de componentes eletrônicos e de máquinas e equipamentos, ou seja, setores econômicos que requerem alto grau de concentração de capital e de

$5 \mathrm{~A}$ maioria das indústrias dos estados do Nordeste do Brasil serve como exemplo.

6 Este é o caso, por exemplo, da produção de tungstênio do Rio Grande do Norte e, em maior proporção, de Rondônia cuja exportação tem relativamente aumentado devido à demanda chinesa.

7 Todavia, essa é apenas uma parte do debate que, até o presente momento, se desenvolve no Brasil entre os que defendem que as ZPEs devem ser instaladas em regiões menos desenvolvidas (Norte e Nordeste, por exemplo) e entre os que defendem que suas instalações seriam muito mais viáveis em regiões de desenvolvimento industrial e de identidade exportadora historicamente mais avançadas como, notadamente, o Sudeste e parte do Sul do país. 
tecnologias nem sempre possíveis às indústrias tradicionais localizadas nas áreas menos desenvolvidas da periferia.

Pelos motivos abordados no parágrafo anterior, dentre outros - como a crescente tendência de aumento da demanda internacional por produtos de maior valor agregado e de alta tecnologia - parece difícil apostar no sucesso das ZPEs através apenas dos incentivos ao capital nacional. Braga (2003, p. 2) afirma categoricamente que:

(...) é parte essencial da política de promoção de exportações a concessão de estímulos fiscais e creditícios às empresas nacionais exportadoras, mas é igualmente importante que a política contenha instrumentos adequados para atrair empresas estrangeiras para aqui se instalarem, e daqui atenderem seus mercados globais.

De acordo com Netto e Braga (2006. pp. 3-4) de forma geral as ZPEs no Brasil têm oferecido os seguintes incentivos:

- Isenção de impostos e contribuições federais (Imposto de Importação, IPI, adicional ao Frete para Renovação da Marinha Mercante, Finsocial e IOF);

- às compras no mercado interno serão atribuídos os mesmos tratamentos fiscal, cambial, creditício e administrativo aplicável às exportações em geral para o exterior, ou seja, gozarão das mesmas isenções de uma exportação normal (relativamente aos impostos federais);

- o Imposto de Renda sobre lucros será aquele vigente na data da aprovação do projeto na ZPE, "ressalvado tratamento legal mais favorável instituído posteriormente", assegurando, sob este aspecto, a "manutenção das regras do jogo";

- as empresas gozarão também de liberdade cambial (não precisam fechar câmbio) e de procedimentos administrativos mais simplificados; e os tratamentos fiscal, cambial e administrativo resumidos acima serão assegurados pelo prazo de até 20 anos, que poderá ser estendido, sucessivamente, por períodos iguais ao originalmente concedido.

Ademais, deve-se ainda considerar os efeitos de uma ZPE sobre a dinamização de adensamento industrial composto por produtores e fornecedores nacionais de matérias-primas produzidas no próprio país e muitas vezes nas vizinhanças da referida Zona Franca.

Para aqueles que defendem a importância de ZPEs no processo de crescimento das exportações, na criação de empregos e na geração de renda, além de, sua elevação em âmbito regional, diminuindo assim os desequilíbrios internos, deve-se sempre levar em conta que as experiências de muitos países têm demonstrado que as 
ZPEs induziram com eficiência a criação de fornecedores locais com grande ênfase em pequenas e médias empresas que tentam se inserir no comércio exterior. $O$ fato é que as empresas situadas em determinada ZPE, por questões logísticas, têm dado preferências aos fornecedores locais em detrimento aos de outros países. Para tanto, a maior exigência é que os fornecedores locais atendam suas demandas através de padrões adequados de preço e qualidade internacionais.

Os incentivos à criação e instalação desse tipo de Zona Franca ${ }^{8}$ permitiram que países desenvolvidos como os Estados Unidos, Austrália, Alemanha, Dinamarca etc. e países em desenvolvimento como a China e a Coréia do Sul, dentre outros, conseguiram sustentar com sucesso suas Zonas de Exportação.

De acordo com o mais recente e conhecido estudo sobre Zonas de Processamento de Exportações - "Special Economic Zones: Performance, Lessons Learned, and Implications for Zone Development" -, elaborado pelo Banco Mundial no ano de 2008, o quadro atual das ZPEs pelo mundo tem a seguinte configuração: existem cerca de 2.650 ZPEs que estão instaladas em 135 países. Em conjunto, as referidas Zonas oferecem mais de 68 milhões de empregos diretos e geram, em receitas cambiais líquidas, uma quantia superior a US $\$ 500$ bilhões. Daquele total de ZPEs, 2.300 estão localizadas em países em desenvolvimento e 350 em países desenvolvidos, o que demonstra que esse tipo de política de exportação não é específica para desenvolver áreas subdesenvolvidas. ${ }^{9}$

Em relação ao segundo grupo de países, os Estados Unidos detêm o maior número de ZPEs, 266, conhecidas nacionalmente como "Foreign Trade Zones". O segundo posto é ocupado pelo Japão, com 22 Zonas de Exportação ("Foreign Access Zones"); em terceiro lugar, empatados, a Austrália e a Dinamarca com 10 ZPEs. Esses são apenas alguns dos diversos exemplos citados no referido estudo do Banco Mundial.

8 "Em muitos países, as zonas francas industriais são conhecidas como 'zonas de processamento de exportação' (ZPEs), exatamente para destacar a sua finalidade básica de produzir para exportação." (BRAGA, 2003, p.3)

9 Ver mais sobre o assunto em Projeto de Relocalização da Zona de Processamento de Exportação de Macaíba/RN, fevereiro de 2010. 
No que diz respeito ao primeiro grupo de países, os em desenvolvimento, a China se destaca com 187 ZPEs e o Vietnam com 186. Esses números ajudam a colocar a região da Ásia-Pacífico em primeiro lugar no que tange a quantidade de Zonas de Processamento de Exportação (991). As Américas do Sul e Central, totalizam cerca de 274 ZPEs. O Oriente Médio e o Norte da África figuram com 213 e, a África Subsaariana, com $114^{10}$. (BANCO MUNDIAL, 2008)

Embora exponham outros números sobre as ZPEs espalhadas pelo mundo, as estatísticas realizadas por instituições "independentes" não destoam significativamente das elaboradas pelo Banco Mundial. Em sua pesquisa sobre o tema, a International Labour Organization (ILO) chegou a conclusão que no ano de 2002 já existiam no mundo 3.000 ZPEs das quais 2/3 das mesmas estavam localizadas na China sob variadas designações (zonas econômicas especiais, zonas de desenvolvimento econômico e tecnológico, zonas de processamento de exportações e zonas de fronteira) ${ }^{11}$.

Assim, pode-se afirmar que as ZPEs como instrumento de crescimento e desenvolvimento econômico foram largamente utilizadas por países de todos os continentes. Foi, em boa medida, através delas que os "Tigres Asiáticos" (como, por exemplo, Cingapura, Coréia do Sul e Taiwan) nos anos de 1980 e 1990 impulsionaram suas exportações e, mais recentemente, a China e a Índia.

De passagem, deve ser registrado que as instituições internacionais têm manifestado grande apoio à utilização de Zonas de Processamento de Produção em todo o mundo, algumas inclusive divulgando vastos relatórios onde recomendam o uso daquelas como meio de acelerar o crescimento econômico. Com esses propósitos podem ser citadas as seguintes instituições: Banco Mundial (BM); Organização das Nações Unidas para o Desenvolvimento Industrial (ONIDO); e Organização das Nações

10 Deve-se atentar para o detalhe que se está fazendo referências apenas às Zonas de Processamento de Exportação, mas se for acrescentado às anteriores os demais tipos de Zonas Francas, a China somará, por exemplo, mais de 2.000.

11 Observem que essas estatísticas não são exageradas quando comparadas com a do Banco Mundial (2008). Esse último focou suas pesquisas apenas em ZPEs existentes no mundo e seus efeitos econômicos. O estudo do International Labour Organization (2002) incorporou em sua pesquisa todos os tipos de zonas francas o que fez da China o maior exemplo em âmbito mundial. De acordo ILO apud Braga (2003, p. 3) o número de empregos nas ZPEs era de 22,5 milhões em 1997, saltou para 37 milhões em 2002, dos quais 30 milhões pertenciam exatamente à economia chinesa. 
Unidas para o Comércio e Desenvolvimento (UNCTAD). As duas primeiras elaboraram relatórios específicos para a economia brasileira onde aconselham a instalação de ZPEs.

\section{ZONA DE PROCESSAMENTO DE EXPORTAÇÃO: O DEBATE}

Para os que fazem oposição às ZPEs no Brasil, os argumentos têm basicamente se resumido na defesa de que as empresas que operam naquelas Zonas competem de forma desleal com as demais empresas que não dispõem dos mesmos benefícios fiscais e aduaneiros; que acarretam perdas fiscais; que pertencem a um pensamento ultrapassado da década de 1970; que facilita o contrabando; e que são incompatíveis com as regras da Organização Internacional do Comércio (OMC) e do MERCOSUL etc. Esses argumentos, de acordo com Netto e Braga (2006), não se sustentam diante da atual realidade da economia brasileira e internacional. Os referidos autores afirmam que:

Todos esses argumentos são rigorosamente equivocados/inconsistentes, e nenhum deles resiste a uma análise imparcial e tecnicamente bem fundamentada (...). O fato concreto é que essa resistência atrasou por quase duas décadas o desenvolvimento industrial do país, que poderia estar hoje no grupo dos países de maior desenvolvimento mundial recente. (NETTO E BRAGA, 2006, p. 10)

Assim, para os que defendem as ZPEs, em primeiro lugar, apenas $20 \%$ da produção de uma empresa que opera em ZPE pode ser direcionado ao mercado interno. Essa produção vendida internamente está sujeita às mesmas cargas tributárias e de impostos que incidem sobre qualquer empresa em âmbito nacional. Portanto, preserva-se assim a concorrência entre as empresas que produzem fora e dentro das ZPEs.

Em segundo lugar, a questão das perdas fiscais ocasionadas pelas ZPEs é bastante discutível dado que as ZPEs funcionam como mecanismo de atração de novos capitais nacionais e, sobretudo, estrangeiros que ingressam no país exatamente por conta de sua existência. Essas novas unidades produtivas "irradiam" efeitos positivos sobre o conjunto da economia atraindo outras empresas, aumentando o nível do 
emprego e da renda e, em algumas vezes, da própria receita fiscal quando muitas das novas indústrias atraídas não operam nas referidas ZPEs e sim em suas vizinhanças 0 que, de certa forma, compensaria e mesmo neutralizaria os supostos efeitos negativos das renuncias fiscais. Esses são os efeitos indiretos que uma ZPE pode oferecer. Ademais, os gastos significativos com as instalações e manutenções de ZPEs ocorrem sob a tutela dos governos estaduais e municipais e, em alguns casos, pela própria iniciativa privada, mas não pela União que por lei não pode alocar recursos orçamentários neste tipo de empreendimento.

Em terceiro lugar, não se justificaria para os defensores das ZPEs a acusação de que estas incitam o contrabando. A ZPE se constitui, em sua maioria, de áreas rigorosamente fechadas (vigiadas) e com a presença constante de instituições públicas específicas para o "policiamento" das práticas produtivas e comerciais ilícitas, como é o caso da Receita Federal.

Em quarto lugar, para os que são contra, as ZPEs competem com outros incentivos às exportações já existentes - tais como: drawback $^{12}$ e aeroporto industrial ${ }^{13}$ - o que anula os efeitos positivos daqueles incentivos. Para os defensores, as ZPEs não foram criadas para competir com os atuais incentivos às exportações. Elas complementam os incentivos que hoje são praticados no país e os supera em determinados aspectos, pois concedem até vinte anos de concessão fiscal podendo ser renováveis por igual tempo, um aspecto que diferencia seus incentivos dos demais existentes no país. Ademais, apenas as ZPEs concedem liberdade cambial às empresas instaladas em suas dependências onde não as obriga transformar suas divisas de exportações em moedas nacionais, como anteriormente registrado.

12 O regime aduaneiro especial de drawback foi instituído pelo Decreto Lei no 37, de 21/11/1966. Diz respeito à suspensão ou eliminação de tributos incidentes sobre insumos importados para utilização na produção de produtos que são exportados. O mecanismo funciona como um incentivo às exportações por torná-las mais competitivas no mercado internacional dado a diminuição dos custos de produção. Existem três modalidades de drawback: a isenção, a substituição e restituição.

13 Trata-se de facilitar a instalação de empresas de tecnologia de ponta em áreas próximas a aeroportos que funcionam como uma espécie de corredor exportador. As indústrias terão isenções de impostos federais e estaduais, sobre as importações de componentes e também nas atividades de exportação de produtos acabados de alto valor agregado. O melhor exemplo desse tipo de incentivo no Brasil está localizado em Confins (Aeroporto Internacional Tancredo Neves), na Região Metropolitana de Belo Horizonte. (Cf. www.uai.com.br. Acesso em 17 de março de 2010. 
Em quinto lugar, os críticos das ZPEs alegam que essa estrutura produtiva está historicamente ultrapassada, pois é um fenômeno das décadas de 1960 e 1970. Os defensores das ZPEs contra-argumentam ressaltando que nas décadas passadas as mesmas estavam praticamente voltadas para beneficiar as atividades comerciais. Foram tão importantes que evoluíram nos últimos vinte anos como instrumento de incentivo às atividades industriais e de serviços (turismo), o que evidencia uma evolução quantitativa e qualitativa do fenômeno e não sua negação ou regressão.

Em sexto lugar, para os críticos, as ZPEs são estruturas contrárias à lógica global de abertura e desregulamentação do comércio mundial. Quanto a este aspecto os defensores das ZPEs alegam que se as mesmas são historicamente ultrapassadas. Assim, como se explica o fato de que países desenvolvidos como EUA, Inglaterra (esse, extremante neoliberal), Alemanha etc. e em desenvolvimento como Índia e a China (com mais de 2000 ZPEs de várias modalidades) terem obtido grandes êxitos em tempos de globalização adotando as ZPEs como instrumento de incentivo às exportações?

Ademais, as ZPEs não criam obstáculos ao inexorável processo de abertura das economias nacionais. Muito pelo contrário, contribui para o sucesso do mesmo desde que sirva de atrativo ao Investimento Externo Direto (IED), que proteja o capital nacional exportador respeitando às diretrizes das instituições comerciais internacionais e que funcionem como instrumento de desenvolvimento econômico nacional, o que, de a acordo com os defensores das ZPEs, já é uma realidade internacional.

No que tange especificamente ao Brasil a ZPE ainda é um fenômeno a se manifestar, pelo menos do ponto de vista de sua concretude, apesar de constar em legislação desde 1988 (Decreto-Lei № 2.452/1988) quando foram "criadas" 17 ZPEs, que estão localizadas nas seguintes cidades: Barcarena (PA), São Luiz (MA), Parnaíba $(\mathrm{Pl})$, Fortaleza $(\mathrm{CE})$, Macaíba (RN), João Pessoa (PB), Suape (PE), Aracaju (SE), Ilhéus (BA), Vila Velha (ES), Itaguaí (RJ), Teófilo Otoni (MG), Imbituba (SC), Rio Grande (RS), Araguaína (TO), Cáceres (MT) e Corumbá (MS). Quatro dessas ZPEs as de Teófilo Otoni, Imbituba, Araguaína e Rio Grande - estão com as obras de 
infraestruturas concluídas e prontas para começar a receber empresas ${ }^{14}$. A única ZPE que tem projetos industriais já aprovados (em número de 3) é a de Imbituba - SC, mas ainda está aguardando o alfandegamento ${ }^{15}$. (BRAGA, 2003 e 2006).

No Brasil, os governos estaduais aguardam a definição final do governo federal no sentido de liberar as autorizações para o pleno funcionamento das primeiras ZPEs. Alguns estados (Minas Gerais, Tocantins, Santa Catarina e Rio Grande do Sul) já concluíram suas obras de infraestrutura. Outros estão em processo de negociação para instalação - em suas prováveis ZPEs - de projetos de significado porte industrial, são eles: Maranhão, Ceará, Pernambuco e Rio de Janeiro (projetos de siderurgia) e Espírito Santo e Pernambuco (com projetos de refino de petróleo). Os demais estados nordestinos - Rio Grande do Norte, Paraíba, Piauí, Sergipe e Bahia - estão apressando ao máximo o processo de construção de suas infraestruturas com decisivo apoio do Banco do Nordeste ${ }^{16}$. (NETTO E BRAGA, 2006).

\section{VANTAGENS E DESVANTAGENS DAS ZPES}

Registrada a discussão entre os que defendem e são contrários as ZPEs, cabe também evidenciar a posição oficial do Ministério do Desenvolvimento, Indústria e Comércio Exterior, mesmo que de forma resumida sobre algumas vantagens e desvantagem das operações industriais em ZPEs. Para o referido Ministério pesam sobre as vantagens de operar em ZPES os incentivos fiscais e as simplificações das operações:

(...) o fato de não haver necessidade de licenças, e estar em uma área alfandegada, com desembaraço aduaneiro no próprio local, implica sensível redução dos custos operacionais; há flexibilização nos procedimentos de importação de máquinas, aparelhos, instrumentos e equipamentos, inclusive usados; ao contrário de outros regimes aduaneiros especiais, não há exigência de prazo máximo para efetivação de exportações com usufruto da suspensão de determinados tributos no momento da importação de insumos, bem como não há exigência de Licenças de Importação; em comparação com outros

14 Trata-se de cercas de proteção, instalações para Receita Federal, vias de acessos e sistema de vigilância.

15 Deve-se ter em conta que 14 das 17 ZPEs existentes no país foram criadas no governo de José Sarney e 4 no governo de Itamar Franco. (TRIBUNA DO NORTE, 2008, p. 15)

16 Inicialmente as ZPEs deveriam ser instaladas apenas nos estados mais pobres (Norte e Nordeste do país), porém a Lei no $8.396 / 1992$ foi criada para autorizar suas instalações em outras regiões do país. 
regimes, o grau de confiança é maior para o investidor, uma vez que não se sujeita à revogação e alteração, e tem o prazo mínimo de 20 anos. Em relação às desvantagens, destacam-se: 0 fato dos benefícios das empresas instaladas em ZPEs se restringirem aos expressos na Lei 11.508, as impedem de obter outros incentivos; devido ao seu caráter eminentemente exportador, as ZPEs não são adequadas àqueles que desejam vender seus produtos ao mercado interno; e elevado grau de exigência desde a apresentação da proposta de criação de ZPE. (MIDIC, 2009, ps. 10-11)

Não há nenhuma explicação jurídica para que as ZPEs do Brasil não estejam em pleno funcionamento. A lista de incentivos às mesmas esteve durante os anos de 1988 a 1992, sob as determinações específicas do Decreto-Lei 2.452/1988 que sofreu nova redação a partir da Lei ํㅜ 8.396/1992 que tornava as ZPEs no Brasil mais modernas, porém ainda com certas limitações, como por exemplo, a proibição de venda de determinado percentual da produção no mercado interno. Esse ponto de estrangulamento só foi superado no início dos anos 2000. Ademais, os procedimentos das áreas aduaneira e cambial foram regulamentados pela Receita Federal através da Instrução Normativa no 26/1993 e pela Circular № 1.390/1988 do Banco Central do Brasil. Isto significa que do ponto de vista legal não há impedimento para que as ZPEs funcionem plenamente.

Para os especialistas, o sistema normativo de ZPEs no Brasil sofreu um grande avanço qualitativo no ano de 2001 quando foi elaborado o Projeto de Lei no 5.456 . Esse último trouxera significativas mudanças modernizadoras tornando as ZPEs brasileiras operacionalmente bem mais próximas das estrangeiras, sobretudo pelo fato de permitir que $20 \%$ da produção das ZPEs seja vendida no mercado interno. Nesse sentido, estão expostas abaixo as principais mudanças nas normas que regulamentam as ZPEs no Brasil, permitindo-as que usufruam das mesmas vantagens das ZPEs instalados no restante do mundo:

- Isenção do PIS-PASEP, do COFINS, do PIS-PASEP-Importação e do COFINS-Importação;

- carência do Imposto de Renda nos cinco primeiros anos de operação (10 anos no caso das Regiões Norte e Nordeste);

- permite a venda no mercado doméstico de até $20 \%$ da produção, sendo que esta parcela internalizada deverá pagar integralmente o Imposto de Importação incidente sobre as matérias primas e componentes importados além do IPI, do 
ICMS, do PIS-PASEP, da COFINS, do PIS-PASEP-Importação e da COFINSImportação sobre o preço final do produto $^{17}$ (BRAGA, 2006, p.6 e 7).

Esses últimos dois anos ocorreram intensas discussões entre os governos estaduais e a iniciativa privada com o governo federal no sentido de apressarem as reformulações ainda pendentes na Legislação para que as ZPEs sejam instaladas em caráter de urgência, devido, sobretudo, ao aumento das exportações brasileiras, para a Ásia. Atualmente a nova legislação básica das ZPEs no Brasil é a Lei no 11.508/2007 que trouxe poucas mais importantes mudanças qualitativas em relação às Leis anteriormente estabelecidas. A passagem abaixo resume essas mudanças:

A Lei no 11.508/2007 (com as modificações introduzidas pela Lei $n^{\circ}$ 11.732/2008) corrigiu a maioria dessas restrições. Basicamente, o novo modelo contém os seguintes aperfeiçoamentos: permite venda no mercado interno de até $20 \%$ da renda bruta (pagando-se todos os impostos incidentes na operação); substitui a exigência de desapropriação pela de comprovação da disponibilidade do terreno para implantação da ZPE, abrindo espaço para a propriedade privada da área da ZPE; e elimina as exigências de capital social mínimo, gastos mínimos no mercado interno e objeto social restrito à industrialização de bens - todas de escassa justificação técnica e uma delas (a de gastos mínimos) proibida pelas regras da Organização Mundial de Comércio. (PROJETO DE RELOCALIZAÇÃO DA ZPE DE MACAỈBA/RN, 2010, p. 11)

A Lei $n^{0} 11.508 / 2007$ foi ainda mais abrangente e modernizadora do que as Leis anteriores sobre ZPEs tornando-as muito mais atrativas ao capital pelo fato de ter extinguido a proibição de assunção de ônus pelo Tesouro Nacional; a exigência de alfandegamento da área; a proibição de acesso a outros incentivos (notadamente os relativos à redução de $75 \%$ do imposto de renda, durante a primeira década concedidos às empresas que operarão em ZPEs situadas nas áreas de atuação da SUDAM e da SUDENE); a proibição de acesso ao mercado nacional; a exigência da matriz insumoproduto e a proibição de depreciar bens de capital importado, para efeito do imposto de renda. Ademais, a referida Lei estendeu às empresas localizadas em ZPEs da região Centro Oeste o acesso ao imposto de renda. Ou seja: todas essas modificações colocam as ZPEs brasileiras - do ponto de vista da desburocratização à instalação e

17 Todas as Leis e Decretos acima citados passaram por reformas nos anos mais recentes. O DecretoLei que criou as ZPEs no Brasil (DL no 2.452/1988), que já havia passado por várias reformas, como já registrado no texto, foi substituído pela Lei no 11.508/2007 (com alterações introduzidas pela Lei no $11.732 / 2008)$. 
quanto às operações produtivas - em condições de competição internacional bastante significativas.

No Brasil as ZPEs têm como principal característica serem zonas francas industriais fechadas. Em alguns estados elas são públicas (totalmente pertencentes ao governo estadual ou municipal); em outros, privadas (foram licitadas e passadas a grupos privados); e, na maioria dos casos, mistas (pertencentes aos governos estadual e municipal, associados a grupos privados) (BRAGA, 2003, p. 5). Algumas, mesmo antes de serem instaladas - como a de Macaíba, no Rio Grande do Norte -, nasceram sob a tutela municipal e estadual, porém com grandes perspectivas de suas administrações virem a ser privadas. Atualmente, mais de $60 \%$ das ZPEs existentes no mundo tem gestão privada. Para boa parte dos especialistas no fenômeno essa é uma tendência que deverá continuar pelo fato de saírem mais baratas e por garantirem resultados econômicos mais significativos.

Assim, a recomendação geral para a instalação de uma ZPE é que a mesma seja do tipo Distrito Industrial fechado e que permita a instalação tanto de empresas industriais como comerciais, além de ser priorizado uma gestão privada e não pública.

\section{AS ZONAS DE PROCESSAMENTO DE EXPORTAÇÃO DO RIO GRANDE DO NORTE}

\subsection{ZONA DE PROCESSAMENTO DE EXPORTAÇÃO DE MACAÍBA/RN}

Como as demais ZPEs do país, a de Macaíba também foi criada no ano de 1988 pelo Decreto-Lei 96.989. No referido ano a área onde seria instalada a ZPE era de 200,78 hectares. Todavia, à semelhança das demais ZPEs, a de Macaíba nos anos de 1980 não passou desse estágio devido prioritariamente a dois fatores apontados pelos especialistas: a má qualidade da legislação (que era muito restritiva, como já discutido acima) e devido às resistências de alguns segmentos da indústria e do executivo local que não haviam amadurecido o suficiente quanto ao entendimento da importância de uma ZPE para o desenvolvimento industrial local e regional.

Passados 20 anos de sua criação, a ZPE de Macaíba perdeu a área que foi disponibilizada para sua construção. Porém, no ano de 2006, o governo do Estado do 
Rio Grande do Norte, incentivado pela nova conjuntura nacional e pela disposição do governo federal em reavivar os projetos de instalações de ZPEs em todo o país, encaminhou ao Conselho Nacional das Zonas de Processamento de Exportação (CZPE) uma proposta de relocalização da ZPE do município de Macaíba para o município de São Gonçalo do Amarante. Por diversas razões - como a falta da indicação e discriminação no projeto da nova área - a proposta do Rio Grande do Norte foi negada, o que exigiu do Governo do Estado e da Prefeitura de Macaíba a transferência da provável ZPE de Macaíba para uma outra área do município.

A atual área disponibilizada para a ZPE de Macaíba tem $1.257 .354,53 \mathrm{~m}^{2}$, ou seja, 125,7 hectares. Seu perímetro é de $4.705,49 m$. A área foi disponibilizada mediante desapropriação amigável ${ }^{18}$.

No que tange à logística, o terreno contempla plenamente às normas de instalação, pois se encontra circundado por vias de acessos já estabelecidas. A área fica a $3 \mathrm{~km}$ de duas BRs que se juntam exatamente no município de Macaíba: a BR 304 e a 226. Construída nesta área, a ZPE ficará a $20 \mathrm{~km}$ da capital do estado (Natal) que também é o principal município da Região Metropolitana e a $13 \mathrm{~km}$ do município de São Gonçalo do Amarante onde está instalado o maior aeroporto intermodal do Cone Sul. Ademais, encontra-se a $25 \mathrm{~km}$ do principal porto do estado (o Porto de Natal) e a $12 \mathrm{~km}$ do aeroporto Internacional Augusto Severo. Ou seja, sob os aspectos logísticos a ZPE de Macaíba encontra-se totalmente beneficiada.

No Quadro 1 está exposto o primeiro orçamento de construção da ZPE de Macaíba. Observe-se que devido à infraestrutura já existente nas proximidades da área onde será construída a referida Zona, como registrado no parágrafo acima, apenas $19 \%$ do orçamento de construção da mesma estão comprometidos com a "InfraEstrutura Básica e Redes. O maior percentual do orçamento, aproximadamente $70 \%$, está comprometido com o item "Construção Civil e Pavimentação". Após sua autorização a previsão é de que as obras deverão ser executadas no prazo de 12 meses.

18 A documentação comprobatória encontra-se disponível no trabalho: "Projeto de Relocalização da Zona de Processamento de Exportação de Macaíba/RN", 2010. 
Quadro 1 - Orçamento da Construção do Primeiro Módulo da ZPE de Macaíba (46,6 ha)

\begin{tabular}{|c|c|c|c|c|c|}
\hline ITEM & DESCRIÇÃO & NID. & QUANT & PÇ. UNIT. & TOTAL (R\$) \\
\hline 1.0 & PROJETOS & & & & $800.000,00$ \\
\hline 1.1 & Projeto de Alfandegamento & $\mathrm{Cj}$. & 1,00 & $100.000,00$ & $100.000,00$ \\
\hline 1.2 & & $\mathrm{Cj}$. & 1,00 & $200.000,00$ & $200.000,00$ \\
\hline 1.3 & & $\mathrm{Cj}$. & 1,00 & $200.000,00$ & $200.000,00$ \\
\hline 1.4 & & Cj. & 1,00 & $300.000,00$ & $300.000,00$ \\
\hline 2.0 & CONST. CIVIL/PAVIMENTAÇÃO & & & & $6.283 .768,61$ \\
\hline 2.1 & TERRAPLENAGEM & & & & \\
\hline 2.1 .1 & Desmatamento Mecânico & $\mathrm{M}^{2}$ & $466.600,00$ & 0,25 & 116650,00 \\
\hline 2.1 .2 & Corte & $\mathrm{M}^{3}$ & $118.272,45$ & 3,50 & $413.953,58$ \\
\hline 2.1 .3 & Aterro Compensado, Inclusive compactação mecânica & $\mathrm{M}^{3}$ & $118.272,45$ & 8,50 & $1.005 .315,83$ \\
\hline 2.2 & CONTORNOS & & & & \\
\hline 2.2 .1 & Cercas & $\mathrm{M}$ & $6.539,76$ & 45,00 & 294289,20 \\
\hline 2.2 .2$. & Grade de Fechamento em Metalon, $\mathrm{H}=3,00 \mathrm{~m}$ & $\mathrm{M}^{2}$ & $2.178,00$ & 120,00 & $261.360,00$ \\
\hline 2.3 & GUARITA E COBERTURA & & & & \\
\hline 2.3 .1 & Guarita & $\mathrm{M}^{2}$ & 24,00 & $1.300,00$ & $31.200,00$ \\
\hline 2.3 .2 & Cobertura para Autos & $\mathrm{M}^{2}$ & 112,00 & 500,00 & $56.000,00$ \\
\hline 2.4 & PÓRTICO DE ENTRADA & & & & \\
\hline 2.4 .1 & Construção do Pórtico de Entrada & Und & 1,00 & $50.000,00$ & $50.000,00$ \\
\hline 2.5 & ARRUAMENTO/PAVIMENTAÇÃO/DRENAGEM & & & & \\
\hline 2.5 .1 & Pavimentação de Ruas, Passeios e Drenagem & $\mathrm{M}^{2}$ & 42.560 & 48,00 & $2.042 .880,00$ \\
\hline 2.6 & $\begin{array}{l}\text { PRÉDIOS ADMINISTRTIVOS/INSTALAÇÕES } \\
\text { ADUANEIRAS }\end{array}$ & & & & \\
\hline 2.6 .1 & Administração ZPE & $\mathrm{M}^{2}$ & 130,00 & $1.120,00$ & $145.600,00$ \\
\hline 2.6 .2 & Instalações Aduaneiras & $\mathrm{M}^{2}$ & 320,00 & $1.120,00$ & $358.400,00$ \\
\hline 2.6 .3 & Restaurante & $\mathrm{M}^{2}$ & 96,00 & $1.120,00$ & $107.520,00$ \\
\hline 2.6 .4$. & Serviços Gerais & $\mathrm{M}^{2}$ & 96,00 & 700,00 & $67.200,00$ \\
\hline 2.6 .5 & Depósitos & $\mathrm{M}^{2}$ & 550,00 & 700,00 & $385.000,00$ \\
\hline 2.6 .6 & Oficina & $\mathrm{M}^{2}$ & 312,00 & 700,00 & $218.400,00$ \\
\hline 2.7 & BALANÇA & & & & \\
\hline 2.7 .1 & Fornecimento e Instalação de Balança & Und & 1,00 & $40.000,00$ & $40.000,00$ \\
\hline 2.8 & SISTEMA DE SEGURANÇA/VEÍCULO & & & & \\
\hline 2.8 .1 & Inst. do Sist. de Seguraça/ Veículo & $\mathrm{Cj}$. & 1,00 & $320.000,00$ & $320.000,00$ \\
\hline 2.9 & URBANIZAÇÃO/PAISAGISMO (Inc.Calçada e Iluminação) & & & & \\
\hline 2.9 .1 & Urbanização de Ruas, Paisagismo, calçadas e lluminação & Cj. & 1,00 & $370.000,00$ & $370.000,00$ \\
\hline 3.0 & INFRA-ESTRUTURA BÁSICA- REDES & & & & $1.710 .000,00$ \\
\hline 3.1 & ÁGUA - POÇOS - RESERVATÓRIOS - REDES + ETA & VB & 1,00 & $410.000,00$ & $410.000,00$ \\
\hline 3.2 & SANEAMENTO - REDE +ETE & VB & 1,00 & $530.000,000$ & $530.000,000$ \\
\hline 3.3 & ENERGIA - SE +REDE & VB & 1,00 & $480.000,00$ & $480.000,00$ \\
\hline 3.4 & TELECOMUNICAÇÕES -REDE - CENTRAL & VB & 1,00 & $70.000,00$ & $70.000,00$ \\
\hline 3.5 & OUTROS & VB & 1,00 & $220.000,00$ & $220.000,00$ \\
\hline \multirow[t]{2}{*}{4.0} & PROMOÇÃO E OUTRAS DESPESAS & VB & 1,00 & & $200.000,00$ \\
\hline & TOTAL GERAL & & & & $8.993768,61$ \\
\hline
\end{tabular}

Fonte: Projeto de Relocalização da Zona de Processamento de Exportação de Macaíba/RN, 2010, p. 85.

Como a pauta de exportação da ZPE tem que obrigatoriamente ser composta de produtos manufaturados e semi-manufaturados, nela só deveria ser instaladas empresas industriais que não exportam commodities. Como no Rio Grande do Norte as empresas exportadoras operam, em sua maioria, com baixa e média intensidade 
tecnológica, a ZPE de Macaíba poderá - e deverá - se constituir numa grande oportunidade para viabilizar e apressar uma mudança estrutural na pauta de produção e de exportação do estado na direção de produtos de maior valor agregado.

De passagem, deve ser registrado que o Documento de Relocalização da Zona de Processamento de Exportação de Macaíba (2010), parte do princípio de que a ZPE que será instalada no município deverá ter uma estrutura produtiva baseada na que hoje prevalece no estado. Esse argumento precisa ser avaliado com certo cuidado, pois uma ZPE tem que, impreterivelmente, servir como instrumento catalisador de capitais que produzam e exportam produtos de alto valor agregado e que atraia, sobretudo, capitais estrangeiros que invertam em setores intensivos em tecnologia. Pode ser encontrada no documento a seguinte passagem:

De uma maneira geral, a definição do perfil industrial de uma ZPE se baseia na estrutura produtiva pré-existente na região, uma vez que estes mecanismos tendem predominantemente a reforçar o potencial produtivo da área, em vez de induzir a instalação de atividades que não correspondam às vocações naturais da região. Costuma ser levada em conta também a pauta de exportação, dado que as empresas instaladas nas ZPEs são obrigadas a direcionar para 0 mercado externo a maior parte de sua produção. (PROJETO DE RELOCALIZAÇÃO DA ZONA DE PROCESSAMENTO DE EXPORTAÇÃO DE MACAÍBA, 2010, p. 80)

Como já mencionado em parágrafos anteriores, a capacidade de exportação das indústrias do estado ainda é reduzida. Nela, também é insignificante a participação do capital estrangeiro. Ou seja, o grande desafio da ZPE de Macaíba será o de viabilizar o reequipamento das indústrias do estado, com nova base de capital fixo (máquinas e equipamentos e matérias-primas mais sofisticadas) e ao mesmo tempo atrair o capital estrangeiro de setores mais dinâmicos em ciência e tecnologia. Isso tudo numa ZPE que boa parte da estrutura produtiva tenderá a ser composta das chamadas indústrias tradicionais.

Quanto às atuais empresas localizadas no Rio Grande do Norte que têm potencial para se instalar na ZPE de Macaíba pode-se afirmar que muito provavelmente serão aquelas que fazem parte do conjunto de empresas que "historicamente" exportam para o exterior parte de sua produção, tais como: as de vestuário e confecções; de beneficiamento de frutas tropicais; de confeitaria; de beneficiamento de peixes e 
camarões; e as têxteis. Desse conjunto de empresas apenas as do setor têxtil produzem com tecnologia de padrão internacional. Com o auxílio da Tabela 1 fica claro entender a importância do setor têxtil estadual nas exportações. Dentre as empresas exportadoras do Rio Grande do Norte no ano de 2009, a Coteminas S.A. figura na primeira colocação. Observe-se que as três empresas que se aproximam da Coteminas são empresas do setor de alimentos considerados setores tradicionais da indústria.

Tabela 1- Exportações do RN por Principais Empresas Exportadoras (2008/2009)

\begin{tabular}{|c|c|c|c|c|c|c|}
\hline \multirow[b]{2}{*}{ Ord. } & \multirow[b]{2}{*}{ Descrição } & \multicolumn{2}{|c|}{$\begin{array}{l}2009 \\
\text { US\$ }\end{array}$} & \multicolumn{2}{|c|}{$\begin{array}{l}2008 \\
\text { US\$ }\end{array}$} & \multirow{2}{*}{$\begin{array}{c}\text { Var\% } \\
\text { 09/ago }\end{array}$} \\
\hline & & 1.000 & Part $\%$ & 1.000 & Part \% & \\
\hline & Total & 258.104 & 100 & 347.524 & 100 & $-25,7$ \\
\hline & Total das Empresas & 243.593 & 94,4 & 304.580 & 87,6 & $-20,0$ \\
\hline 1 & Coteminas & 22.352 & 8,7 & 20.063 & 5,8 & 11,4 \\
\hline 2 & A Ferreira Indústria de alimentos Ltda & 20.044 & 7,8 & 17.637 & 5,1 & 13,7 \\
\hline 3 & Simas Indústria de alimento S.A. & 17.073 & 6,6 & 19.796 & 5,7 & $-13,8$ \\
\hline 4 & Tavares de Melo Açúcar e Alcool & 16.223 & 6,3 & 28.198 & 8,1 & $-42,5$ \\
\hline 5 & Camanor Produtos Marinho Ltda. & 15.126 & 5,9 & 19.629 & 5,7 & $-22,9$ \\
\hline 6 & Usibras Usina Brasileira de Óleo & 15.126 & 5,9 & 17.281 & 5 & $-12,5$ \\
\hline 7 & Salinor - Salinas do Nordeste S.A. & 14.128 & 5,5 & 2.776 & 1 & 409,0 \\
\hline 8 & Del Monte Fresh Produce Brasiul Ltda. & 13.849 & 5,4 & 14.283 & 4,1 & $-3,0$ \\
\hline 9 & Coopyfrutas-Cooperativas & 13.347 & 5,2 & 14.809 & 4,3 & $-9,9$ \\
\hline 10 & Olam Brasil Ltda & 8.599 & 3,3 & 11.476 & 3,3 & $-25,1$ \\
\hline 11 & Petrobrás Distribuidora S.A. & 8.423 & 3,7 & 27.194 & 7,8 & $-69,0$ \\
\hline 12 & Bollo Brasil Produção e comer Frutas & 7.264 & 2,8 & 6.993 & 2 & 3,9 \\
\hline 13 & Finobrasa Agroindústria S.A & 6.006 & 2,3 & 4.806 & 1,4 & 25,0 \\
\hline 14 & Laminor S.A & 5.824 & 2,3 & 4.115 & 1,2 & 41,5 \\
\hline 15 & Mata Fresca Ltda & 5.286 & 2,1 & 5.430 & 1,6 & $-2,7$ \\
\hline 16 & Nolem Comercial Ltda & 4.786 & 1,9 & 28.347 & 8,2 & $-83,1$ \\
\hline 17 & Salinas Indústria de Pesca Ltda. & 3.643 & 1,4 & 4.523 & 1,3 & $-19,5$ \\
\hline 18 & Afical - a Ferreira Indústria & 3.612 & 1,4 & 1.386 & 0,4 & 160,6 \\
\hline 19 & C Y Matsumoto & 3.188 & 1,2 & 3.651 & 1,1 & $-12,7$ \\
\hline 20 & RCM Indústria e Comércio de Subpro & 3.156 & 1,2 & 1.723 & 0,5 & 83,2 \\
\hline 21 & Demais Empresas & 51.047 & 20 & 93.409 & 27 & $-0,45$ \\
\hline
\end{tabular}

FONTE: MDIC - Extraído do Projeto de Relocalização da Zona de Processamento de Exportação de Macaíba/RN, 2010.

Ou seja, para que a ZPE de Macaíba funcione como uma ZPE de características internacionais terá que necessariamente induzir a introjeção de novas e modernas tecnologias nas empresas (tradicionais) que atualmente exportam para o exterior e apressar, sobretudo, a entrada de indústrias estrangeiras com a finalidade de produzir bens de alto valor agregado. Esse parece ser o desafio. 
Atualmente as exportações do Rio Grande do Norte são destinadas para uma razoável quantidade de países. No ano de 2009 suas exportações tiveram como destino os Estados Unidos, que importaram cerca de um terço das exportações do estado. Para a Holanda foram destinadas 13,7\%; para Espanha, 8,5\%; para o Reino Unido, 6,9\%; para a França, 6,2\%; e, para a Argentina, 4,9\% ${ }^{19}$. Esses poderão continuar sendo os potenciais destinos das exportações da Zona de Processamento de Exportação de Macaíba.

O município de Macaíba tem $512 \mathrm{~km}^{2}$. Possui uma população estimada, para o ano de 2009, de 66.380 mil habitantes, com uma ocupação total de aproximadamente 10.482 pessoas. O município tem uma economia muito frágil tanto no que concerne à agropecuária quanto ao que concerne à indústria.

Historicamente a produção agropecuária foi preponderante, sobretudo na agricultura de frutas como o caju, a laranja, a manga e o coco. Na pecuária vigorou a produção extensiva de gado bovino ${ }^{20}$.

Quanto à indústria de Macaíba pode-se afirmar que ainda é incipiente prevalecendo a indústria do setor têxtil, de alimentos e de bebidas que contam com os incentivos do Programa de Apoio ao Desenvolvimento Industrial do Rio Grande do Norte (PROADI). Apenas a título de breve exemplo, na Tabela 2 podem ser observadas as principais indústrias exportadoras do município. Dentre as mesmas destacam-se, a exemplo das exportações do conjunto do estado, os produtos de indústrias tradicionais.

Os Cobertores e Mantas representaram no ano de 2008, 23,9\% das exportações do município seguidos pelos produtos da indústria alimentícia. Dentre esses últimos, tiveram destaques os produtos de Confeitaria (sem cacau), que representaram 18,6\% das exportações, e os Bombons, Caramelos, Confeitaria e Pastilhas (sem cacau) com peso de 18,4\% nas exportações municipais. As Roupas de Cama de Fibras Sintéticas também representaram expressivo percentual nas exportações de Macaíba, 10,5\%.

19 Ver mais sobre o assunto em: Projeto de Relocalização da Zona de Processamento de Exportação de Macaíba, 2010, p. 86.

20 As informações censitárias em relação à agropecuária do município de Macaíba, no período 20022006, indicam que tanto a produção de frutas quanto a pecuária são demasiadamente frágeis e tiveram um comportamento decrescentes no referido período. Ver maiores detalhes sobre o assunto em Projeto de Relocalização da Zona de Processamento de Exportação de Macaíba, 2010. 
Tabela 2 - Principais Produtos Exportados por Macaíba - 2007-2008

\begin{tabular}{|c|c|c|c|c|c|c|}
\hline \multirow[b]{2}{*}{ Ord. } & \multirow{2}{*}{ Descrição } & \multicolumn{2}{|c|}{2009} & \multicolumn{2}{|c|}{2008} & \multirow[b]{2}{*}{ Var\% } \\
\hline & & US\$ & Part\% & US\$ & Part\% & \\
\hline & & \multicolumn{2}{|l|}{1.000} & \multicolumn{2}{|l|}{1.000} & $2008 / 2007$ \\
\hline & $\begin{array}{c}\text { Total dos Principais Produtos } \\
\text { Exportados }\end{array}$ & $43.968,9$ & 100 & $44.933,4$ & 100,0 & $-2,2$ \\
\hline$\overline{1.1}$ & Cobertores e Mantas de algodão & $10.494,7$ & 23,9 & $9.247,3$ & 20,6 & 13,5 \\
\hline 2 & $\begin{array}{l}\text { Outros Produtos de Confeitaria Sem } \\
\text { Cacau }\end{array}$ & $8.157,7$ & 18,6 & $9.144,0$ & 20,4 & $-10,8$ \\
\hline 3 & $\begin{array}{l}\text { Bombons, Caramelos, Confeitarias e } \\
\text { Pastilhas, Sem Cacau }\end{array}$ & $8.089,7$ & 18,4 & $6.747,4$ & 15,0 & 19,9 \\
\hline 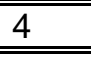 & Roupas de Cama de Fibras Sintéticas & $4.614,0$ & 10,5 & $4.795,7$ & 10,7 & $-3,8$ \\
\hline$\overline{5}$ & Gomas de Mascar Sem Cacau & $3.549,9$ & 8,1 & $5.663,4$ & 12,6 & $-37,3$ \\
\hline 6 & Mamões Papaias Frescos & $2.992,8$ & 6,8 & $3.103,4$ & 6,9 & $-3,6$ \\
\hline 7 & $\begin{array}{l}\text { Roupas de Cama de Algodão } \\
\text { estampadas }\end{array}$ & $2.304,2$ & 5,2 & $1.167,0$ & 2,6 & 97,5 \\
\hline 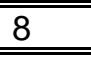 & Mel Natural & $1.386,2$ & 3,2 & 0,0 & 0,0 & 0,0 \\
\hline 9 & Camisetas T-Shirts & $1.024,5$ & 2,3 & $3.137,4$ & 7,0 & $-67,3$ \\
\hline 10 & Outras Roupas de Algodão & 461,2 & 1,1 & 500,9 & 1,1 & $-7,9$ \\
\hline 11 & $\begin{array}{l}\text { Roupas de Mesa de fibras Síntét. } \\
\text { /Artif. Exc. De Malha }\end{array}$ & 337,5 & 0,8 & 268,1 & 0,6 & 25,9 \\
\hline 12 & $\begin{array}{l}\text { Outros Produtos Hortículas, Frescos } \\
\text { ou Refrigerados }\end{array}$ & 211,1 & 0,5 & 445,8 & 1,0 & $-52,7$ \\
\hline 13 & Óleos essenciais de Vetiver & 160,5 & 0,4 & 279,6 & 0,6 & $-42,6$ \\
\hline 14 & Colchas de Algodão, Exc. De Malha & 97,7 & 0,2 & 60,4 & 0,1 & 61,8 \\
\hline 15 & $\begin{array}{l}\text { Cobertores e Mantas de Fibras Sínt. } \\
\text { Não Elétricos } \\
\end{array}$ & 32,3 & 0,1 & 0,0 & 0,0 & 0,0 \\
\hline 16 & $\begin{array}{l}\text { Outras Roupas de Cama de Fibras } \\
\text { Sint./Artificiais }\end{array}$ & 27,0 & 0,1 & 113,3 & 0,3 & $-76,2$ \\
\hline 17 & Melões Frescos & 24,3 & 0,1 & 0,0 & 0,0 & 0,0 \\
\hline 18 & $\begin{array}{l}\text { Outros Impressos: } \\
\text { Publicações/Catalogados Comerciais }\end{array}$ & 2,0 & 0,0 & 0,6 & 0,0 & 239,0 \\
\hline 19 & $\begin{array}{l}\text { Outros Sacos, Bolsas e Cartichos de } \\
\text { Outros Plásticos }\end{array}$ & 1,5 & 0,0 & 41,1 & 0,1 & $-96,4$ \\
\hline 20 & $\begin{array}{l}\text { Etiquetas de Papel ou Cartão } \\
\text { Impressos }\end{array}$ & 0,1 & 0,0 & 0,0 & 0,0 & 0,0 \\
\hline 21 & Outros & 0,0 & 0,0 & 0,2 & 0,0 & 0,0 \\
\hline
\end{tabular}

Fonte: MDIC - Extraído do Projeto de Relocalização da Zona de Processamento de Exportação de Macaíba, 2010, p. 75.

Deve ainda ser destacado que Macaíba, apesar de sua incipiente produção industrial, exporta para mais de 20 países de todos os continentes. Vale registrar que $64,4 \%$ das exportações do município, referentes ao ano de 2008, tiveram como destino a economia Norte-Americana e $17,8 \%$ a economia Argentina. 
Os dados expostos nos dois parágrafos anteriores demonstram que já existe uma razoável conexão econômica entre o município de Macaíba e a economia internacional. A ZPE que nele será instalada deverá solidificar quantitativa e qualitativamente seu parque industrial. Mas, o fundamental é que a referida Zona irradie suas influências desenvolvimentistas para além do município sede e para além da Região Metropolitana de Nata (RMN), pois um instrumento de crescimento econômico como uma ZPE, de acordo com a literatura e os experimentos internacionais, cria encadeamentos produtivos para trás (backward linkages) e efeitos de transbordamentos (spillover effects). Os encadeamentos para trás estão diretamente ligados à contratação de mão de obra, de serviços, matérias primas e bens de capital e, os de transbordamento, dizem respeito à difusão tecnológica e de novos métodos produtivos e de gestão atualmente utilizados pelas empresas em todo o mundo.

Sobre a empresa administradora recairá a responsabilidade para apresentar os estudos específicos sobre os impactos ambientais do empreendimento conhecido como Estudo de Impacto Ambiental (EIA) e, ao mesmo tempo, o Relatório de Impacto Sobre o Meio Ambiental (RIMA). Na atual fase de sua "implantação" está sendo exigido que o órgão do estado responsável pelo controle ambiental reconheça através de parecer favorável que as atividades produtivas da referida Zona de Macaíba não colocam em risco a preservação do ecossistema local.

Na perspectiva de evitar os impactos negativos ao meio ambiente, no projeto de criação da ZPE de Macaíba já está previsto que a corrente dos efluentes líquidos geradas pelas indústrias e instalações internas à ZPE serão conduzidas a uma Estação de Tratamento de Efluentes - ETE, para tratamento dos prováveis agentes poluentes presentes nas correntes, de forma que alcancem valores mínimos correspondentes aos limites de emissão que estão especificados na Resolução CZPE no 2/2009. Ao esgoto sanitário também foi dedicado um rigoroso cuidado, pois no projeto já está previsto seu tratamento antes de ser lançado na rede receptora. Além desses cuidados exigidos pela Legislação em vigor, de acordo com o Projeto de Relocalização da Zona de Processamento de Exportação de Macaíba (2010, p. 94), "está prevista a implantação e manutenção de Planos para Situações de Emergência Ambiental e Planos de 
Contingência Ambiental, inclusive de combate a incêndios, coordenados pela empresa administradora da ZPE".

\subsection{A ZONA DE PROCESSAMENTO DE EXPORTAÇÃO DE ASSÚ}

A ZPE de Assú foi aprovada pelo Conselho Nacional de Zonas de Processamento de Exportação (CZPE) no dia 8 de dezembro de 2009 e está sendo cogitada como um instrumento de grande importância para o crescimento econômico dos municípios do Semi-árido potiguar. A mesma encontra-se a $230 \mathrm{~km}$ da capital e será instalada numa área de aproximadamente 1 mil hectares, em uma região de grande interação com territórios dos estados vizinhos - como o Oeste da Paraíba e o Leste do Ceará.

A referida ZPE, popularmente conhecida como ZPE do Sertão, terá como área de influência as Zonas Homogêneas Mossoroense de Caicó, de Currais Novos e das Serras Centrais, além do próprio Vale do Assú. Seus fundadores acreditam que o sucesso da ZPE do Sertão será garantido pelo processamento de minerais tais como: calcário, caulim, sal, ouro, minério, ferro, gemas e rochas ornamentais. Devem ser somadas aos produtos anteriormente citados as atividades concernentes à produção de petróleo e gás, frutas tropicais (que já estão caracterizadas como produção para exportação) e a de frutos do mar.

De acordo com o Ministério do Desenvolvimento, Indústria e Comércio Exterior (MDIC) que, como já citado anteriormente, preside o CZPE, a ZPE de Assú deverá dar início as suas atividades 21 meses após o término das obras de infraestrutura. Essas obras foram orçadas em cerca de $R \$ 18$ milhões. Para a proponente do projeto de instalação da ZPE, a Prefeitura Municipal, a área onde será instalada a ZPE fica ao lado da BR-304 e já conta com estrutura básica, água tratada e encanada, cabeamento ótico, energia, sinal de telefonia celular e internet. No momento a mais importante via de escoamento de sua futura produção deverá ser pela BR 304. Todavia, de acordo com a prefeitura do município, há uma grande possibilidade da construção de um modal ferroviário que deverá contar com a incisiva participação do capital inglês. 
Ademais, deve ser registrado que já foi realizado um estudo específico sobre a viabilidade econômica da ZPE que apresentou ao CZPE o potencial mercado internacional da mesma. No referido estudo foram destacados os seguintes países como demandadores da produção da ZPE de Assú: Estados Unidos, Holanda, Reino Unido, Espanha, França, Itália, Líbia, Canadá, Argentina e Nigéria ${ }^{21}$. Mas, dada o potencial mineral do Município a China é uma potencial demandadora de sua produção.

Embora de suma importância para o crescimento da economia do interior e para a integração da economia do estado como um todo deve-se ter em mente que o desafio de criar e manter uma ZPE pautada preponderantemente na produção e exportação de produtos minerais não é simples.

Por um lado, esta ZPE sofrerá todos os problemas de seu pioneirismo internacional, dado que não se tem conhecimento de casos parecidos. Mas, por outro lado, poderá atrair para a região - principalmente para a produção de minérios - 0 grande capital internacional.

A produção de minério da região - sobre a qual a ZPE terá influência decisiva ainda é significativamente carente de tecnologia e técnicas modernas de produção. Esses são, inclusive, problemas estruturais que pairaram sobre o setor a mais de meio século. Como uma das finalidades da ZPE é exatamente atrair o capital estrangeiro, esse pode ser um bom momento histórico para corrigir a atual deficiência, aumentando a produção e a qualidade do minério da região, diminuindo seus custos de produção, criando novos postos de ocupação etc. Ademais, vale lembrar que a China voltou a demandar minério do mundo inteiro, inclusive do Rio Grande do Norte. Neste sentido, o próprio capital Asiático poderia ser atraído para a ZPE do Sertão, produzindo e exportando para o resto do mundo a partir dos benefícios fiscais oferecidos pela ZPE. Em troca teríamos empregos e, se bem acordado, acesso a tecnologias de extração e qualificação mineral. 


\section{CONSIDERAÇÕES FINAIS}

É importante ter claro que embora vários estados e a União concedam concessão de benefícios para as exportações, o país ainda sofre pela inexistência de uma política específica com essa finalidade. Essa distinção é de fundamental importância, pois dela resulta a elaboração adequada de instrumentos a serem mobilizados com a finalidade de incentivar e manter as condições ideais de apoio à produção para exportação. Uma política específica de exportações deverá conter instrumentos capazes de estimular as empresas nacionais a exportar e ao mesmo tempo atrair empresas estrangeiras para se estabelecerem no território nacional. Esses são, pode-se dizer, os efeitos universais de uma ZPEs.

Nesse sentido, procurou-se de forma incisiva deixar claro que a utilização da ZPE como instrumento de dinamização da produção e, sobretudo, das exportações, não é uma proposta vazia de conteúdo e de experimentos reais de sucesso. Obviamente que nem todas as ZPES do mundo foram de sucesso absoluto. Todavia, os exemplos internacionais ratificam que se bem contextualizadas - isto é, se forem praticadas de forma coerente com uma política de desenvolvimento nacional mais ampla e obedecendo as regras do comércio internacional - a utilização da ZPE pode contribuir decisivamente para modificar a quantidade e a qualidade do que se produz em determinadas regiões e países.

A ZPE é hoje um instrumento de política de exportação utilizada por vários países do mundo (desenvolvidos ou emergentes, capitalistas ou pós-comunistas), independente de seu sistema de poder. Como anteriormente registrado no corpo do presente texto, as ZPEs funcionam como uma excelente alternativa de estímulo às exportações devido ao fato delas criarem determinado ambiente propício à atração de empresas estrangeiras voltadas para a exportação; por que criam as condições equivalentes de produção e exportação das empresas nacionais vis a vis às suas concorrentes estrangeiras, no que concerne ao acesso a insumos a preços internacionais etc.; e também por possibilitar o adensamento de empresas domésticas que produzirão em suas vizinhanças fazendo com que se manifestem seus efeitos de transbordamentos. 
Dessa forma, as ZPEs devem ser utilizadas por atenderem a vários propósitos tais como: contribuem para o fortalecimento do balanço de pagamentos; criam empregos sem ameaçar as empresas localizadas em outras regiões do país; e contribuem para amenizar os desequilíbrios regionais. Ademais, as ZPEs favorecem a transferência e difusão de tecnologia e de práticas gerenciais mais modernas.

Todavia, para o MDIC, embora as ZPEs funcionem como uma ferramenta de política para o crescimento das exportações e desenvolvimento regional, o sucesso das mesmas não pode ficar atrelado apenas a edificação de uma boa infraestrutura, da simplificação de procedimentos administrativos e da segurança jurídica, "mas também da integração de ações estratégicas na contribuição das estruturas produtivas e sociais das regiões em que serão instaladas".

No Rio Grande do Norte as expectativas para que suas ZPEs atinjam os objetivos esperados de um instrumento de política de exportação desse porte são muito grandes. Para o estado o desafio é ainda maior devido sua incipiente estrutura produtiva industrial. Todavia, a infraestrutura que no momento está sendo construída (estradas federais e estaduais, portos e aeroportos, saneamento e urbanização) constitui-se em fortes indícios de que todos os esforços necessários estão sendo colocados em prática na perspectiva de mobilização do estado, das prefeituras, da iniciativa privada e de toda população para que as ZPEs do estado sejam em breve um atuante instrumento de crescimento econômico.

\section{REFERÊNCIAS}

BRAGA, $H$. A experiência internacional de zonas francas e a necessidade de promoção das exportações. (ABRAZPE), 2002. Disponível em: < http://www.abrazpe.org.br/index.php/zpesbrasil>. Acesso em 15 nov. 2017.

BRASIL. Ministério do Desenvolvimento, Indústria e Comércio Exterior (MDIC). Secretaria de Comércio Exterior (SECEX). Manual ZPE. Brasília: MDIC, 2009. 53 p. Disponível em: <http://www.assescontms.com.br/manual.pdf>. Acesso em: 18 ago. 2017.

DELFIM NETTO, A.; BRAGA, H. C. O “ABC" das zonas de processamento de exportação (ZPEs). ABRAZPE), 2006. Disponível em: < http://www.abrazpe.org.br/index.php/zpesbrasil/> Acesso em: 05 fev. 2017 
INSTITUTO DE ESTUDOS PARA O DESENVOLVIMENTO INDUSTRIAL (IEDI). Economias Emergentes: Incentivos Para a Atração de Investimentos. São Paulo: ledi, 2002. 49 p. Disponível em:

<http://www.iedi.org.br/admin_ori/pdf/eco_emergentes.pdf>. Acesso em: 21 dez. 2015.

INTERNATIONAL LABOUR OFFICE (ILO). Committee on Employment and Social Policy. Employment and social policy in respect of export processing zones (EPZs). Suíça, Genebra: International Labour Office, 2003. 21 p. Disponível em: $<$ https://www.ilo.org/public/english/standards/relm/gb/docs/gb286/pdf/esp-3.pdf>. Acesso em: 26 jul. 2015.

PELIN, Elir.; SILBER, Simão D.; ÂNGELO, Ivo do P. Zonas de processamento de exportação: o debate. São Paulo: MIC/IPE/USP, 1989.

TRIBUNA DO NORTE: Caderno de Economia. Infra-estrutura. Natal, 08 jun. 2008. p. 1 a 31.

TRIBUNA DO NORTE: Caderno de Economia. ZPE não garante desenvolvimento. Natal, 11 abr. 2010. p. 3.

TRIBUNA DO NORTE: Caderno de Economia. Uma ZPE para o semi-árido. Natal, 10 mar. 2010. p. 3. 